\title{
Avaliação da Composição Química e da Digestibilidade in Vitro da Mistura Aveia IAPAR 61 (Avena strigosa Schreb) + Ervilha Forrageira (Pisum arvense L.) em Diferentes Alturas sob Pastejo ${ }^{1}$
}

\section{Márcia Mascarenhas Grise ${ }^{2}$, Ulysses Cecato ${ }^{3}$, Anibal de Moraes ${ }^{4}$, Marco Weber do Canto ${ }^{3}$, Elias Nunes Martins ${ }^{3}$, Adelino Pelissari ${ }^{4}$, Rodrigo Tábora Mira ${ }^{5}$}

\footnotetext{
RESUMO - O objetivo do trabalho foi avaliar o efeito das alturas $(8,9 ; 10,0 ; 11,2 ; 11,8 ; 13,3 ; 13,6 ; 14,6 ; 18,2 \mathrm{~cm})$ de pastos consorciados de aveia IAPAR 61 (Avena strigosa Schreb cv IAPAR 61) com ervilha forrageira (Pisum arvense L.) sob pastejo sobre a relação folha/colmo (F/C), os teores de proteína bruta (PB), fibra em detergente neutro (FDN) e fibra em detergente ácido (FDA) e a digestibilidade in vitro da matéria seca (DIVMS) e da matéria orgânica (DIVMO). O delineamento experimental usado foi o inteiramente casualizado, com duas repetições. A relação F/C não foi influenciada pela altura do pasto, porém apresentou comportamento quadrático com o avanço na maturidade do pasto. Os teores de $\mathrm{PB}$ apresentaram comportamento quadrático ao longo do período experimental, devido à interação entre altura do pasto e o tempo. Os teores de FDN e FDA mostraram um comportamento quadrático ao longo do período experimental, ocorrendo uma diminuição dos mesmos quando as plantas se apresentavam mais baixas e, uma elevação, quando as plantas estavam mais altas, isto ocorreu em função da interação das variáveis tempo e altura. A DIVMS e a DIVMO tiveram incrementos lineares em função do aumento da altura do pasto, porém com comportamento quadrático no tempo (dias) em todas as alturas, sendo mais elevadas nas alturas intermediárias do pasto.
}

Palavras-chave: digestibilidade da matéria orgânica, digestibilidade da matéria seca, fibra em detergente ácido, fibra em detergente neutro, proteína bruta, relação folha/colmo

\section{Evaluation of Chemical Composition and inVitro Digestibility of Mixture of Oat IAPAR 61 (Avena strigosa Schreb cv IAPAR 61) + Field Pea (Pisum arvense L.) under Grazing in Different Sward Heights}

\begin{abstract}
The objective of this work was to evaluate the effect of different sward heights $(8.9,10.0,11.2,11.8 ; 13.3 ; 13.6 ; 14.6$; $18.2 \mathrm{~cm}$ ) in the mixture of black oat IAPAR 61 (Avena strigosa Schreb cv IAPAR 61) + field pea (Pisum arvense L.), under grazing, on leaf/ stem ratio (L/S), crude protein (CP), neutral detergent fiber (NDF) and acid detergent fiber (ADF) contents and dry matter (DMIVD) and of organic matter (OMIVD) in vitro digestibility. A completely randomized experimental design with two replicates was used. $\mathrm{L} / \mathrm{S}$ ratio was not influenced by sward height, although it presented quadratic behavior with the progress of maturity of the pasture. CP content presented quadratic behavior during the experimental period, in function of the interaction between sward heights and the time. NDF and ADF contents had a quadratic behavior during the experimental period, with the occurrence of a decrease of it when the plants were shorter and an increase when the plants were higher, due the interaction between time and heights. IVDMD and IVOMD presented linear increments as a result of the increase of sward height, and a quadratic behavior as a consequence of the time in all sward heights, being higher in the average ones.
\end{abstract}

Key Words: acid detergent fiber, crude protein, dry matter digestibility, leaf/stem ratio, neutral detergent fiber, organic matter digestibility

\section{Introdução}

Entre as alternativas para solucionar o problema de disponibilidade de forragem no outono - inverno, em grande parte do território brasileiro, o uso de misturas de gramíneas e leguminosas tem proporcionado a manutenção de níveis adequados de ganho animal (QUADROS e MARASCHIN, 1987), em virtude do valor nutritivo deste consórcio.

Pastagens mantidas sob diferentes alturas apresentam diferentes níveis de oferta de forragem, as quais podem afetar a produção e a qualidade do pasto, devendo haver, portanto, ajuste na oferta de forragem, levando a aumentos em qualidade e produtividade, $\mathrm{e}$

\footnotetext{
1 Parte da dissertação de Mestrado em Zootecnia do primeiro autor - Universidade Estadual de Maringá-UEM.

2 Enga -Agra . Mestre em Zootecnia/UEM.

3 Professor do Departamento de Zootecnia da Universidade Estadual de Maringá - Av. Colombo, 5790, 87020-900, Maringá-PR. E.mail: ucecato@uem.br

4 Professor do Departamento de Fitotecnia - Universidade Federal do Paraná - Curitiba-PR.

5 Médico Veterinário da Universidade Federal do Paraná - Curitiba-PR.
} 
melhor equilíbrio da composição botânica do pasto (IDO, 1997).

Segundo BORTOLO (1999), o resíduo do pasto exerce um efeito importante na qualidade da forragem, por modificar a estrutura do pasto por meio da participação dos componentes folha, colmo e material morto. Estes são os componentes estruturais que determinam a qualidade da forragem, havendo redução na qualidade do pasto com o aumento da MS disponível, devido às mudanças nas proporções de material verde das plantas e do material senescente. $\mathrm{O}$ avanço na maturidade do pasto também influi na qualidade da forragem, à medida que altera a relação $\mathrm{F} / \mathrm{C}$, pois tanto a porcentagem de PB quanto a DIVMO são maiores na porção superior e nas folhas do que nas camadas inferiores ou nos colmos das plantas (MORAES e MARASCHIN, 1988).

A redução na qualidade da forragem é conseqüência natural da maturidade da planta, que é acompanhada por lignificação dos tecidos, o que também provoca diminuição no teor de proteína e glicídios digestíveis (MOTT, 1973). MOOJEN (1991) mostrou, em sua pesquisa, relação linear negativa entre a porcentagem de $\mathrm{PB}$ e oferta de forragem (OF), sendo a qualidade da forragem reduzida com o aumento de MS/ha.

O incremento da proporção de folhas na matéria seca total melhora sua digestibilidade e aumenta a ingestão de matéria seca e o ganho médio diário dos animais. Em geral, além do maior teor de PB, as folhas possuem menores teores de FDN, FDA e lignina que os caules ou colmos das plantas forrageiras (VAN SOEST, 1982).

Segundo SÁ (1984), a aveia preta cv. IAPAR 61 apresenta teores de PB próximos a 18\%, entretanto valores superiores foram encontrados por outros pesquisadores (MARTINEZ e COSTA, 1988; FONTANELI e PIOVEZAN, 1991). O teor de FDA encontrado no trabalho de CECATO et al. (1998), para o cultivar IAPAR 61, foi, em média, $28 \%$ na MS.

Com relação à ervilha forrageira (Pisum arvense $\mathrm{L}$.), XAVIER et al. (1998) encontraram teor de PB até $22,4 \%$ da MS.

QUADROS (1984), avaliando o desempenho animal em uma mistura de aveia (Avena strigosa Schreb) + azevém + trevo vesiculoso, sob pastejo com lotação variável, e mantendo uma oferta de forragem de $6 \%$ do peso vivo, registrou valores de 14 a $19 \%$ de PB e 64 a $72 \%$ de DIVMO, respectivamente. Em trabalho semelhante, ROSO e RESTLE (1998) encontraram teores de 18,88 a $20,31 \%$ PB e de 56,94 a $67,47 \%$
DIVMO para misturas de aveia + azevém, triticale (Triticum rimpaui Mac Key) + azevém, e centeio (Secale cereale $)+$ azevém, respectivamente.

Face à boa capacidade produtiva e qualitativa da aveia, observada em experimentos de corte, e ao desconhecimento do potencial qualitativo da mistura aveia (Avena strigosa Schreb) + ervilha forrageira (Pisum arvense L.), sob pastejo, o objetivo deste trabalho foi avaliar o efeito das alturas do pasto sobre a relação $\mathrm{F} / \mathrm{C}$ e as características qualitativas $\mathrm{PB}$, FDN, FDA, DIVMS e DIVMO de um consórcio de aveia IAPAR 61 e ervilha forrageira sob pastejo.

\section{Material e Métodos}

O experimento foi conduzido no Noroeste do Paraná. Esta região situa-se a $23^{\circ} 25^{\prime}$ de latitude Sul, $51^{\circ} 55^{\prime}$ de longitude Oeste e $554,9 \mathrm{~m}$ de altitude. O clima predominante, segundo CORRÊA (1996), é classificado subtropical úmido, mesotérmico, com verões quentes, geadas pouco freqüentes, com tendência de concentração das chuvas nos meses de verão (Cfa). O solo foi caracterizado como podzólico vermelho amarelo distrófico, com a seguinte composição química: $\mathrm{pH}$ $\left(\mathrm{CaCl}_{2}\right)=4,53 ; \mathrm{Al}^{+3}\left(\mathrm{cmol}^{2} / \mathrm{dm}^{3}\right)=0,24 ; \mathrm{H}+\mathrm{Al}$ $(\mathrm{cmol} 2 / \mathrm{dm} 3)=4,17 ; \mathrm{Ca}^{+2}+\mathrm{Mg}^{+2}\left(\mathrm{cmol}^{2} / \mathrm{dm}^{3}\right)=2,22 ;$ $\mathrm{Ca}^{+2}\left(\mathrm{cmol}^{2} / \mathrm{dm}^{3}\right)=1,42 ; \mathrm{K}+\left(\mathrm{cmol}^{2} / \mathrm{dm}^{3}\right)=0,15 ;$ $\mathrm{T}\left(\mathrm{cmol}^{2} / \mathrm{dm}^{3}\right)=6,39 ; \mathrm{P}\left(\mathrm{mg} / \mathrm{dm}^{3}\right)=7,18 ; \mathrm{C}\left(\mathrm{g} / \mathrm{dm}^{3}\right)=$ 9,23; $\mathrm{pH}(\mathrm{SPM})=6,25 ; \mathrm{V}(\%)=37,99$.

Antes da implantação do experimento, a área, inicialmente de pasto degradado, foi utilizada com a sucessão de culturas: soja (verão 97), aveia + ervilhaca (inverno 97) e milho (verão 1998). A área experimental foi de 6,4 hectares, constituída de oito piquetes, com área de 0,8 ha cada, acrescidos de dois piquetes adicionais adjacentes para mantença dos animais reguladores (put and take).

A adubação da área foi realizada utilizando-se $230 \mathrm{~kg}$ do adubo formulado 8-30-20 (NPK) por hectare; mais $16 \mathrm{~kg} / \mathrm{ha}$ de nitrogênio aplicados a lanço logo após o plantio e $50 \mathrm{~kg} / \mathrm{ha}$ de nitrogênio, 30 dias após a germinação, usando-se uréia. No estabelecimento, em 13/05/98, foi feito o plantio direto na palha, utilizando-se $40 \mathrm{~kg}$ de sementes/ha de cada uma das espécies, cinco dias após a dessecação dos restos da cultura anterior.

O experimento foi constituído de quatro tratamentos de altura de pasto, monitorados com o uso de um disco medidor (BRANSBY et al., 1977; GRIGGS e STRINGER, 1988; RAYBURN e RAYBURN, 1988). Os tratamentos, altura do pasto, previstos 
inicialmente foram 4, 8, 12 e $16 \mathrm{~cm}$, porém as alturas reais ocorridas durante o pastejo foram: 8,$9 ; 10,0$; 11,$2 ; 11,8 ; 13,3 ; 13,6 ; 14,6 ; 18,2 \mathrm{~cm}$. Para a manutenção destas, utilizou-se a técnica de pastejo de lotação variável, com carga variável, usando novilhos nelore, com ajustes de carga animal semanalmente, utilizando-se o disco medidor de pasto. Para isso foram realizadas três calibrações, obtendo-se uma equação de regressão entre a altura do disco e o resíduo de matéria seca naquele momento.

A cada 21 dias, foram coletadas rente ao solo, ao acaso, numa área de $0,02 \mathrm{~m}^{2}$, dez amostras por piquete, e destas foram retiradas duas amostras compostas para a determinação da relação $\mathrm{F} / \mathrm{C}$ e a qualidade do pasto. De uma subamostra foi feita a separação entre lâmina verde de aveia (altura da lígula) e do colmo e entre os folíolos da ervilha e o caule. Posteriormente, estas frações foram secas em estufa com circulação de ar forçado a $60^{\circ} \mathrm{C}$, por 72 horas, determinando-se os respectivos pesos seco. Da outra subamostra o material foi seco em estufa e, posteriormente, moído em moinho com peneira de $1 \mathrm{~mm}$.

As análises de DIVMS e DIVMO foram realizadas conforme metodologia de TILLEY e TERRY (1963) no Laboratório de Nutrição Animal do Departamento de Zootecnia da Universidade Estadual de Maringá. As análises dos teores de PB, FDN e FDA foram feitas utilizando-se o equipamento NIRS (Near Infra Red Spectro), no Laboratório de Nutrição Animal da Universidade Federal do Paraná.

Avaliaram-se os parâmetros por meio de análise de regressão, utilizando-se o programa SAEG (EUCLYDES, 1983), em um delineamento experimental inteiramente casualizado, com duas repetições. O modelo estatístico para a análise dos resultados na pasto foi:

$$
\mathrm{Y}_{\mathrm{ijk}}=\mu+\mathrm{b}_{1} \mathrm{~A}_{\mathrm{i}}+\mathrm{b}_{2} \mathrm{~A}_{\mathrm{i}}^{2}+\mathrm{b}_{3} \mathrm{~T}_{\mathrm{j}}+\mathrm{b}_{4} \mathrm{~T}_{\mathrm{j}}^{2}+\mathrm{b}_{5}
$$

em que $Y_{i j}=$ valor observado das variáveis, no piquete $\mathrm{j}$, recebendo tratamento $\mathrm{i} ; \mu=$ constante geral; $\mathrm{A}=$ altura do pasto; $\mathrm{T}=$ efeito do tempo de ciclo de vida da planta; $b_{1}=$ coeficiente linear de regressão da variável y, em função da altura do pasto; $b_{2}=$ coeficiente quadrático de regressão da variável y, em função da altura do pasto; $\mathrm{b}_{3}=$ coeficiente linear de regressão da variável y em função do tempo; $b_{4}=$ coeficiente quadrático de regressão da variável y, em função do tempo; $\mathrm{b}_{5}=$ coeficiente da variável y, em função da interação entre altura e tempo; $\mathrm{e}_{\mathrm{ijk}}=$ erro aleatório associado a cada observação $\mathrm{Y}_{\mathrm{ijk}}$.

\section{Resultados e Discussão}

A relação $\mathrm{F} / \mathrm{C}$ não sofreu efeito $(\mathrm{P}>0,05)$ da altura do pasto, sendo esses resultados semelhantes aos de CANTO (1994), que não obteve efeito significativo entre a relação $\mathrm{F} / \mathrm{C}$ e os níveis de resíduo de MS em um pasto de azevém + trevo branco (Tabela 1).

À medida que a pasto avançou no seu estádio de maturidade, com o passar do tempo, a relação F/C diminuiu em todos as alturas, como pode ser observado na Figura 1.

Em geral, com a elevação da temperatura, as plantas começaram a diferenciar o meristema apical e alongar o colmo, o que permite a redução da relação F/C (LANGER, 1963). Resultado como este também foi observado em Coastcross-1 (Cynodon dactylon (L.) Pers) por BORTOLO (1999). Isto deve influenciar a qualidade do pasto, modificando a composição química e DIVMS e DIVMO, refletindo-se no desempenho animal (KORTE et al., 1987), pois a fração folha possui menos componentes estruturais, como a lignina, que os colmos (VAN SOEST, 1982).

Os valores médios da relação $\mathrm{F} / \mathrm{C}$ variaram de 1,13 a 2,0 (Tabela 1) e, portanto, foram similares àqueles encontrados por CANTO (1994), com espécies de inverno.

Os teores de $\mathrm{PB}$ apresentaram comportamento linear decrescente $(\mathrm{P}<0,05)$, à medida que aumentou a altura do pasto, e quadrático $(\mathrm{P}<0,05)$, ao longo do tempo experimental, com interação entre as variáveis tempo e altura do pasto (Figura 2).

Tabela 1 - Relação folha/colmo (F/C) em um pasto de aveia IAPAR 61 + ervilha forrageira, em função da altura do pasto

Table 1 - Leaf/stem ratio in a mixture of oat IAPAR $61+$ field pea, in function of sward height

\begin{tabular}{lcccc}
\hline $\begin{array}{l}\text { Altura }(\mathrm{cm}) \\
\text { Sward } \\
\text { height }(\mathrm{cm})\end{array}$ & \multicolumn{3}{c}{$\begin{array}{c}\mathrm{F} / \mathrm{C} \\
\text { L/S }\end{array}$} \\
\cline { 2 - 5 } & $08 / 07 / 98$ & $29 / 07 / 98$ & $22 / 08 / 98$ & $\begin{array}{c}\text { Média } \\
\text { Average }\end{array}$ \\
\hline 8,93 & 2,15 & 0,74 & 3,10 & 2,00 \\
10,02 & 1,80 & 0,66 & 1,27 & 1,24 \\
11,27 & 2,57 & 0,56 & 1,15 & 1,43 \\
11,88 & 2,05 & 0,65 & 0,77 & 1,16 \\
13,37 & 2,92 & 1,08 & 0,62 & 1,54 \\
13,62 & 2,09 & 0,71 & 0,59 & 1,13 \\
14,66 & 2,23 & 0,94 & 1,20 & 1,46 \\
18,27 & 2,72 & 0,71 & 0,91 & 1,45 \\
\hline
\end{tabular}




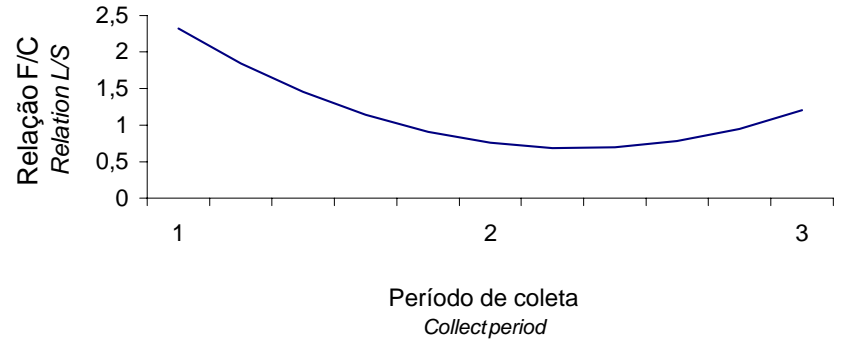

Figura 1 - Relação folha/colmo (F/C) em um pasto de aveia IAPAR 61 + ervilha forrageira, em função do período experimental $(1=8 / 7,2=29 / 7,3=22 / 8)$. $\mathrm{Y}=5,88047-4,5641^{*} T+1,00137 T^{2} R^{2}=0,64 \mathrm{P}<0,05$

Figure 1 - Leaf/stem (L/S) ratio in a oat IAPAR 61 + field pea pasture, according to experimental period.

Os resultados da literatura, em geral, mostram que ocorre redução na percentagem de $\mathrm{PB}$ com o avanço do estádio de desenvolvimento das plantas forrageiras, ou com o aumento da matéria seca, ou do resíduo pós-pastejo (MOOJEN, 1991). A redução dos teores de PB, nas maiores alturas, explica-se pelo maior envelhecimento de parte da forragem disponível, associado à maior fração de forragem senescente, maior proporção de colmos com considerável desenvolvimento de tecidos estruturais.

Nas menores alturas, em função da manutenção do pastejo mais baixo, a rebrota constituia-se de folhas e maior número de perfilhos, permitindo que a forragem apresentasse maior teor de PB. Nas maiores alturas, ocorreu o inverso, o pasto mantinha sua estrutura, principalmente de colmo, apresentando valores de PB inferiores, o que explica a interação entre tempo e altura.

Os teores médios de PB observados variaram de 14,5 a $21,8 \%$ para as alturas de 18,27 e $8,92 \mathrm{~cm}$, respectivamente, podendo ser considerados bons do ponto de vista da nutrição animal e equivalentes aos encontrados por QUADROS (1984), CECATO et al. (1998) e FONTANELI e PIOVEZAM (1991).

Os teores de FDN tiveram comportamento linear $(\mathrm{P}<0,05)$, em relação ao aumento da altura, e quadrático $(\mathrm{P}<0,05)$ para o tempo de crescimento das plantas. Houve interação entre as variáveis tempo e altura (Figura 3).

Essa resposta está associada ao fato de que, nas menores alturas, ao longo do tempo, ocorreu rebrota mais efetiva e constante de perfilhos e folhas, havendo redução da FDN onde os animais estavam coletando

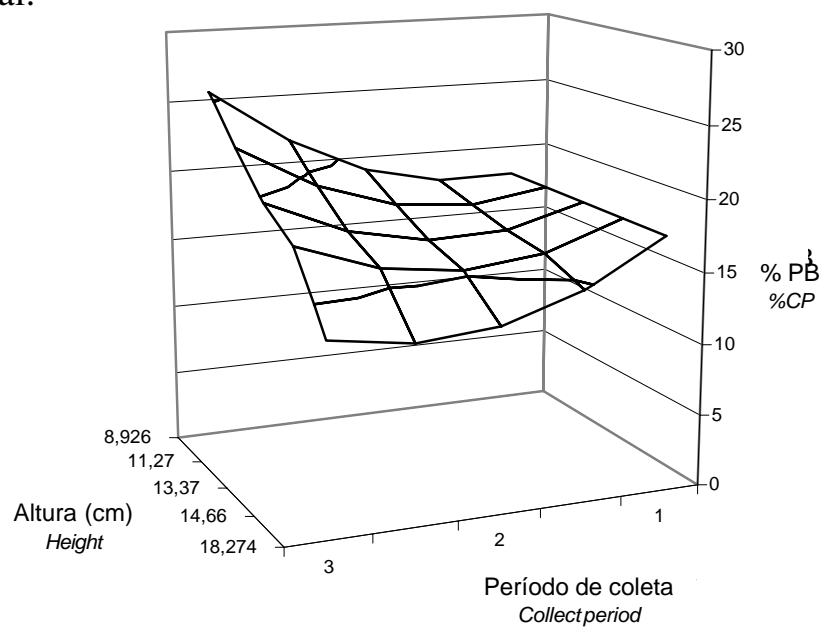

Figura 2 - Teor de proteína bruta (PB) em pasto de aveia IAPAR 61 + ervilha forrageira, em função da altura do pasto $(\mathrm{cm})$ e do tempo experimental $(1=8 / 7$, $2=29 / 7,3=22 / 8) . P<0,05 ; R^{2}=0,64 ; Y=16,2283-$ $0,948222 T+2,65624 T^{2}+0,649549 A-0,655340 T^{*} A$.

Figura 2 - Crude protein content (CP) in a oat IAPAR $61+$ field pea pasture, according to sward height and experimental period.

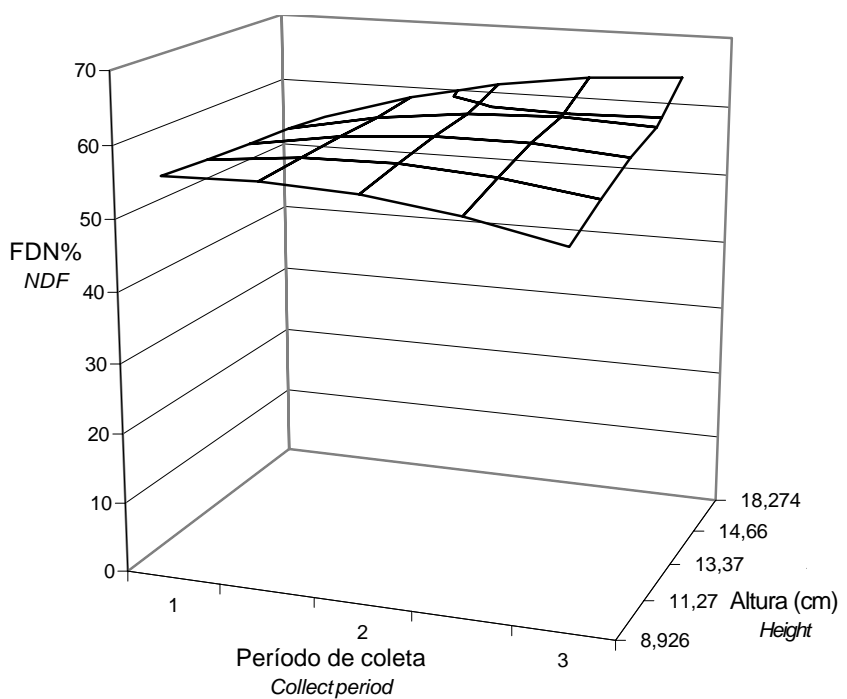

Figura 3 - Teor de fibra em detergente neutro (FDN) em um pasto de aveia IAPAR 61 + ervilha forrageira, em função da altura do pasto $(\mathrm{cm})$ e do período experimental $(1=8 / 7,2=29 / 7,3=22 / 8) . \quad P<0,05$ $Y=61,3216-1,11212 T-2,03749 T^{2}$. $0,956322 A+0,761512 T^{\star} A \quad R^{2}=0,55$.

Figure 3 - Neutral detergent fiber content (NDF) in a oat IAPAR 61 + field pea pasture, according to sward height and experimental period. 
Rev. bras. zootec.

forragem mais tenra. Porém, nas maiores alturas, ao longo do período experimental, como a estrutura do pasto foi mantida e houve o aparecimento de material senescente, ocorreu incremento no conteúdo de parede celular das plantas (WILSON, 1994), aumentando, conseqüentemente, o teor de FDN da forragem (VAN SOEST, 1982).

Os aumentos nos teores de FDN, à medida que se incrementou a altura do pasto, foram comparáveis aos encontrados por IDO (1997), o que se deve ao fato de os teores de FDN de uma forragem aumentarem durante seu desenvolvimento, sendo maior no colmo que nas folhas e maior nas gramíneas que nas leguminosas (VAN SOEST, 1982).

Estes resultados também, em parte, podem ser explicados pela relação $\mathrm{F} / \mathrm{C}$; na primeira data de coleta, quando as plantas apresentavam elevada relação F/C, reduzidos teores de FDN. Por outro lado, devido à queda na relação $\mathrm{F} / \mathrm{C}$, com o tempo, houve incremento dos teores de FDN. Os teores de FDN, em média, variaram de 54,0 a $60,6 \%$ nas alturas de 8,9 e $18,2 \mathrm{~cm}$, respectivamente. Estes valores foram superiores àqueles encontrados por IDO (1997), que trabalhou com um pasto consorciado de inverno, nas pressões de pastejo de 3,5 a 19,4\% peso vivo.

Os teores de FDA tiveram comportamento linear $(\mathrm{P}>0,05)$ tanto para o tempo de crescimento quanto

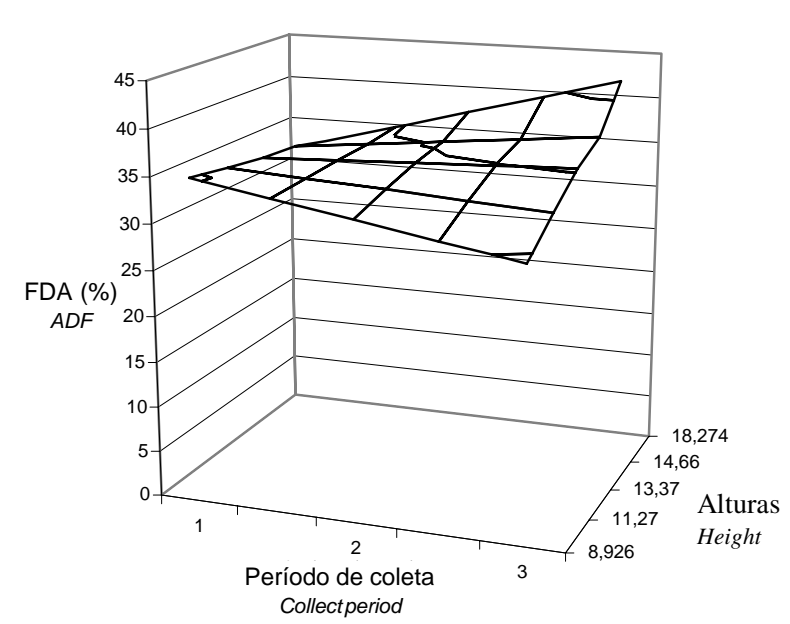

Figura 4 - Teor de fibra em detergente ácido (FDA) em pasto de aveia IAPAR61 + ervilha forrageira, em função da altura do pasto $(\mathrm{cm})$ e do período experimental $(1=8 / 7,2=29 / 7,3=22 / 8) . P<0,05 ; Y=48,0487$ $10,0957 \mathrm{~T}-1,11135 \mathrm{~A}+0,806294 \mathrm{~T}^{\star} \mathrm{A} ; \mathrm{R}^{2}=0,41$

Figure 4 - Acid detergent fiber content (NDF) in a oat IAPAR $61+$ field pea pasture, according to sward height and experimental period. para altura do pasto, ocorrendo interação entre essas duas variáveis, conforme pode ser observado na Figura 4.

Os fatos discutidos em relação à FDN, em grande parte, explicam esse comportamento para a FDA, uma vez que esta é componente da FDN. Isso se torna mais evidente, pois observa-se incremento similar de, aproximadamente, $6 \%$ nos valores de FDN e FDA nas alturas de 8,9 a $18,2 \mathrm{~cm}$.

Os aumentos nos teores de FDA, à medida que se aumenta a altura do pasto, foram comparáveis aos encontrados por IDO (1997) e devem-se ao fato de os teores de FDA assim como os de FDN de uma forragem aumentarem durante seu desenvolvimento, pelo incremento de tecido estrutural, sendo maior no colmo que nas folhas e maior nas gramíneas que nas leguminosas (VAN SOEST, 1982).

Os teores de FDA encontrados no presente trabalho variaram de 31,4 a $37,5 \%$ para as alturas de 8,9 e $18,2 \mathrm{~cm}$, respectivamente. Estes valores de FDA foram superiores àqueles encontrados para aveia IAPAR 61, obtidos por CECATO et al. (1998) e SARTIet al. (1994), sob corte. IDO (1997), que trabalhou com um pasto de azevém e leguminosas de inverno, nas pressões de pastejo de 3,5 a 19,4\% PV, encontrou teores de 29,5\% de FDA.

As plantas apresentaram comportamento quadrático $(\mathrm{P}<0,05)$ para a DIVMS em todas as alturas de pasto,

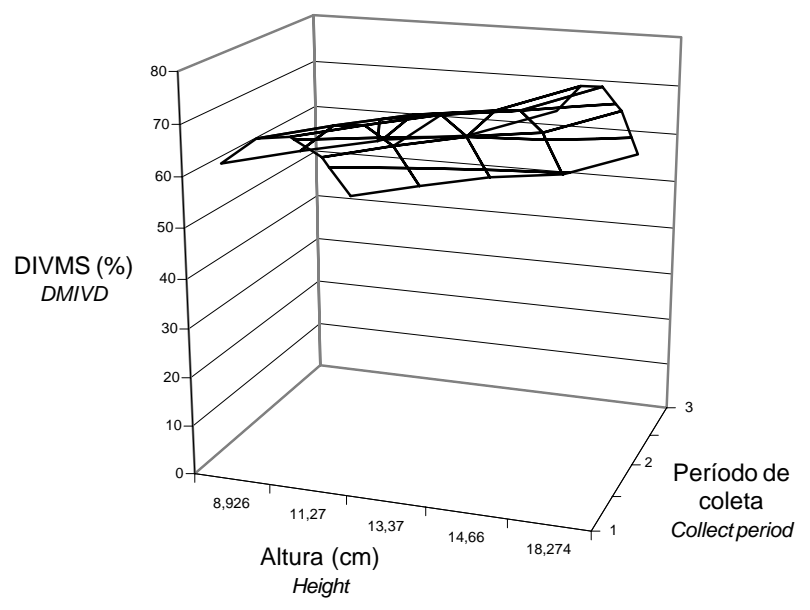

Figura 5 - Digestibilidade in vitro da matéria seca (DIVMS) em pasto de aveia IAPAR61 + ervilha forrageira, emfunção da altura do pasto $(\mathrm{cm})$ e do período experimental $(1=8 / 7$, $2=29 / 7,3=22 / 8) . P<0,05 ; \mathrm{Y}=33,1886+1,56227 \mathrm{~A}+$ $25,2590 \mathrm{~T}-9,15398 \mathrm{~T}^{2} ; \mathrm{R}^{2}=0,67$.

Figure 5 - In vitro dry matter digestibility (DMIVD) in a oat IAPAR $61+$ field pea pasture, according to sward height and experimental period. 
com o passar do período experimental, e linear crescente $(\mathrm{P}<0,05)$, em qualquer época de amostragem da menor para a maior altura do pasto, como pode ser observado na Figura 5.

Os teores de DIVMS variaram, em média, de 53,0 a $69,7 \%$ nas alturas de 8,9 a $18,2 \mathrm{~cm}$, respectivamente; estes valores podem ser considerados normais em espécies forrageiras de inverno (MOTT, 1973). Os maiores teores de DIVMS da forragem nas alturas intermediárias, provavelmente, estão associados à manutenção de crescimento constante do pasto, devido ao maior índice área foliar presente, ocorrendo maior presença de perfilhos e folhas jovens, durante todo o período avaliado. Comportamento semelhante foi encontrado por BORTOLO (1999) em um pasto de Coastcross-1 (Cynodon dactylon (L.) Pers), em função dos níveis residuais de MS e do tempo.

A DIVMO apresentou comportamento quadrático $(\mathrm{P}<0,05)$ em todas as alturas de pastom durante $\mathrm{o}$ período experimental, e linear crescente em qualquer época de amostragem da menor para a maior altura do pasto (Figura 6).

Em relação às alturas do pasto, estes resultados foram similares aos de CANTO et al. (1998), em experimento realizado com forrageiras de inverno com níveis de resíduo de MS, porém contraria àqueles relatados por MOOJEN (1991), que, trabalhando com diversos resíduos de MS em campo nativo, verificou resposta da DIVMO linear negativa ao aumento de níveis de resíduo de MS.

Os valores da DIVMO variaram de 81,6 a $87,6 \%$ nas alturas de 10,0 a $14,6 \mathrm{~cm}$, respectivamente, sendo superiores àqueles registrados por COELHO et al. (1994), que trabalharam com pastagens de aveia preta + ervilhaca. Maiores valores de DIVMO da forragem nas alturas intermediárias, provavelmente, estão associados à manutenção de um crescimento constante do pasto, devido ao maior índice área foliar presente naqueles tratamentos, ocorrendo maior presença de material vegetativo mais tenro com perfilhos e folhas jovens, durante todo o período avaliado.

\section{Conclusões}

Os teores de PB da forragem decresceram, enquanto a FDN e FDA aumentaram com o incremento da altura do pasto nas alturas maiores do pasto, independente de a relação $\mathrm{F} / \mathrm{C}$ ter se mantido semelhante em todas as alturas. Em função do

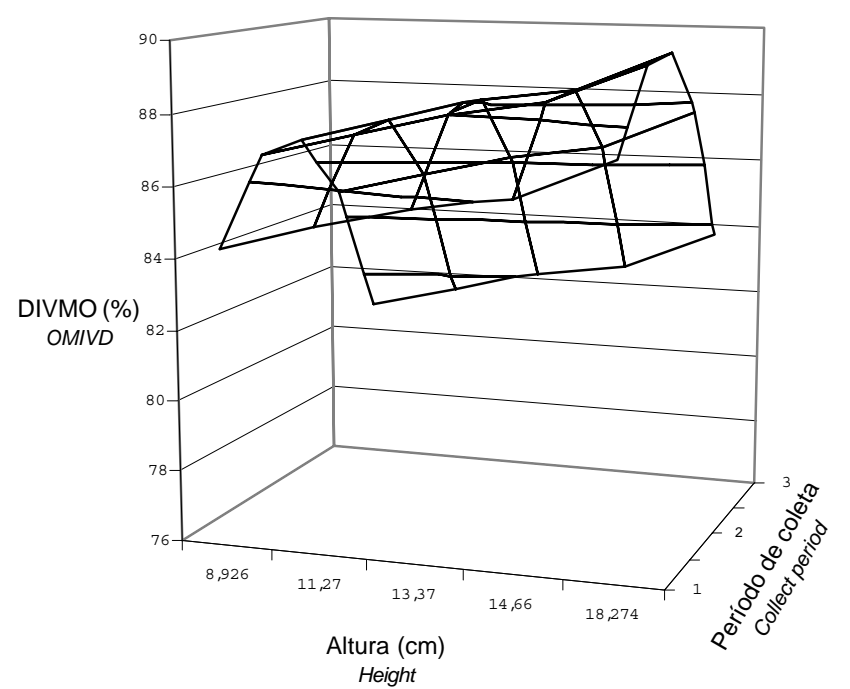

Figura 6 - Digestibilidade in vitro da matéria orgânica (DIVMO) em pasto de aveia IAPAR 61 + ervilha forrageira, em função da altura da pasto $(\mathrm{cm})$ e do tempo experimental $(1=8 / 7,2=29 / 7,3=22 / 8)$. $\mathrm{P}<0,05 \quad \mathrm{Y}=70,9770+0,306025 \mathrm{~A}+14,8492 \mathrm{~T}$ $-4,16031 \mathrm{~T}^{2} \quad \mathrm{R}^{2}=0,42$.

Figure 6 - Organic matter in vitro digestibility (OMIVD) in a oat IAPAR 61 + field pea pasture, according to sward height and the experimental period.

tempo, as plantas apresentaram maior incremento de parede celular (FDN e FDA), enquanto os teores de PB diminuíram, sendo estes acompanhados pela relação F/C. Os valores de DIVMS e DIVMO foram mais elevados nas maiores alturas intermediárias, ocorrendo em ambas elevação de seus teores, em função do tempo.

A qualidade da forragem (PB, FDN, FDA, DIVMS e DIVMO) apresentada pelo consórcio foi muito boa, sendo que as alturas intermediárias podem ser consideradas mais adequadas para o manejo do pasto e, provavelmente, podem refletir em bom desempenho animal.

\section{Agradecimento}

À Universidade Federal do Paraná, Monsanto e à Fazenda Boa Esperança, pela oportunidade na realização deste trabalho. 


\section{Referências Bibliográficas}

BORTOLO, M. Avaliação de pasto de coastcross-1 (Cynodon dactylon (L.) Pers.) em níveis de matéria seca sob pastejo: Maringá, PR: UEM, 1999. 75p. Dissertação (Mestrado em Zootecnia) - Universidade Estadual de Maringá, 1999.

BRANSBY, D.I., MATCHES, A.G., KRAUSE, G.G. 1977. Disk meter for rapid estimation of herbage yield in grazing trials. Agron. J., (69):393-396.

CANTO, M.W. Produção de cordeiros em pasto de azevém (Lolium multiflorum Lam) + trevo branco (Trifolium repens L.) submetida à níveis de resíduos de forragem: Santa Maria, RS: UFSM, 1994. 181p. Dissertação (Mestrado em Zootecnia) - Universidade Federal de Santa Maria, 1994.

CANTO, M.W., MOOJEN, E.L., CARVALHO, P.C.F. et al. 1998. Produção de forragem em uma pasto de azevém (Lolium multiflorum Lam) + trevo branco (Trifolium repens L.) submetida à diferentes níveis de resíduos de matéria seca. R. Bras. Zootec., 27(2):231-237.

CECATO, U., SARTI, L.L., SAKAGUTI, E.S. et al. 1998. Avaliação de cultivares e linhagens de aveia preta (Avena ssp.). Act. Scient., 20(3):347-354.

COELHO F.R.C., QUADROS, F.L.F., COELHO, L.G.M. et al. Avaliação de misturas de estação fria, sobressemeadas em uma pasto natural e submetidas ao pastejo de bovinos. II. Qualidade da forragem. In: REUNIÃO ANUAL DA SOCIEDADE BRASILEIRA DE ZOOTECNIA, 31, 1994, Maringá. Anais...Maringá: SBZ, 1994. p.274.

CORRÊA, A.R. 1996. Forrageiras: aptidão climática do Estado do Paraná. In: CPAF. Forragicultura no Paraná. Londrina: CPAF. p.75-92.

EUCLYDES, R.F. 1983. Manual de utilização do programa SAEG (Sistema de Análise Estatística e Genéticas). Viçosa, MG CPD/UFV. 150p.

FONTANELI, R. S., PIOVEZAN, A J. 1991. Efeitos de cortes no rendimento de forragem e grãos de aveia. Pesq. Agropec. Bras., 26(5):691-697.

GARDNER, A.L. 1968. Medição de atributos das pastagens em experimentos de pastejo. Brasília: Embrapa. p.113-140.

GRIGGS, T.C., STRINGER, W.C. 1988. Production of alfalfa herbage mass using sward height, ground cover, and disk technique. Agron. J., (80):204-208.

IDO, O.T. Efeito de diferentes ofertas de forragem sobre a produção e a qualidade de uma pasto de azevém (Lolium multiflorum Lam) associada com leguminosas de inverno, na Região Sul do Paraná. Curitiba, PR: UFPR, 1997. 81p. Dissertação (Mestrado em Agronomia) - Universidade Federal do Paraná, 1997.

KORTE, C.J., CHU, A.C.P., FIELD, T.R.O. 1987. Feeding Livestock on pasture. In: NICOL, A.M. (Ed.) Pasture production. Hamilton. p.7-20.

LANGER, R.H.M. 1963.Tillering in herbage grasses. Herbage Abstract, 35(3):141-148.

MARTINEZ, H.E.P., COSTA, C. 1988. Rendimento e valor protéico de Avena strigosa cultivada em Selvíria, MS. Pesq. Agropec. Bras., 23(6):653-657.
MOOJEN, E.L. Dinâmica e potencial produtivo de uma pasto nativa do Rio Grande do Sul, submetida a pressões de pastejo, épocas de diferimentos níveis de adubação. Porto Alegre, RS: UFRGS, 1991. 172p. Tese (Doutorado em Zootecnia) - Universidade Federal do Rio Grande do Sul, 1991.

MORAES, A., MARASCHIN, G.E. 1988. Pressões de pastejo e produção animal em milheto cv. comum. Pesq. Agropec. Bras., 23(2):197-205.

MORAES, A. Produtividade animal e dinâmica de uma pasto de pangola (Digitária decumbens stent). Azevém (Lolium multiflorum Lam) e trevo branco (Trifolium respens). L.), submetidas a diferentes pressões de pastejo. Porto Alegre, RS: UFRGS, 1991. 200p. Tese (Doutorado em Zootecnia) Universidade Federal do Rio Grande do Sul, 1991.

MOTT, G.O. 1973. Evaluating forage production. In: HEATH, M.E., METCALTE, D.S., BARNES, R.F. (Eds.). Forages. Ames: Iowa State University. 3.ed. p.126-35.

QUADROS, F.L.P. Desempenho animal em misturas de espécies forrageiras de estação fria. Porto Alegre, RS: UFRGS, 1984. 106 p. Dissertação (Mestrado em Agronomia) - Universidade Federal do Rio Grande do Sul, 1984.

QUADROS, F.L.F., MARASCHIN, G.E. 1987. Desempenho animal em misturas de espécies forrageiras de estação fria. Pesq. Agropec. Bras., 22(5):535-541.

RAYBURN, E.B., RAYBURN, S.B. 1988. A standardized plate meter for estimating pasture mass on farm research trials. Agron. J., 90:238-241.

ROSO, C., RESTLE, J. Produtividade animal em pasto cultivada com gramíneas anuais de estação fria. In: REUNIÃO ANUAL DA SOCIEDADE BRASILEIRA DE ZOOTECNIA, 35, 1998, Botucatu. Anais... Botucatu: SBZ, 1998. p.468-470.

SÁ, J.P.G., 1984. Avaliação de forrageiras de inverno no Norte do Paraná. Fundação Instituto Agronômico do Paraná, 5p. Informe de Pesquisa ${ }^{\circ} 54$.

SARTI, L.L. Avaliação da produção e qualidade de cultivares e linhagens de aveia (Avena spp): Maringá, PR: UEM, 1994. 35p. Monografia (Graduação em Zootecnia) - Universidade Estadual de Maringá, 1994.

TILLEY, J.M.A., TERRY, R.A. 1963. A two stage technique for the "in vitro" digestion of forage crop. J. Brit. Grassland Soc., 18(2):104-111.

VAN SOEST, P.J. 1982. Nutritional ecology of ruminant. New York: Cornell University Press. 373p.

XAVIER, D.F., BOTREL, M.A., FREITAS, V.P. Produção de ervilha forrageira na Zona da Mata de Minas Gerais. In: REUNIÃO ANUAL DA SOCIEDADE BRASILEIRA DE ZOOTECNIA, 35, 1998, Botucatu. Anais... Botucatu: SBZ, 1998. p.498-500.

WILSON, J. R. 1994. Cell wall characteristics in relation to forage by ruminants. J. Agric. Sci., 122:173-182.

Recebido em: 07/07/00

Aceito em: 25/01/01 